\title{
Where South African Sufferers are Treated
}

\section{(Abstracted from “ The Compass," November, 1935.)}

Amatikulu. The Amatikulu Leper Institution, which overlooks the Indian Ocean, was founded in 1902. A new housing scheme has been started and, when complete, it will have the effect of bringing every patient under the immediate care of the medical staff, which, owing to the large area over which the patients are scattered, at present is quite impossible. The new housing scheme will also add much to the comfort of the patients, of whom there are 354.

Bochem. The Bochem Leper Institution is closely connected with the Bochem Hospital, which was founded at an earlier date by the late Mrs. H. M. Franz, a certified nurse from Germany, who with her husband, the late Rev. R. Franz, started missionary work at the Berlin (Lutheran) Mission Station at Leshwane, Pietersburg district, in 1894. Their son, Mr. J. H. G. Franz, is the present Superintendent.

Botsabelo, Basutoland. The Leprosy Institute at Botsabelo was built in 1913 and occupied by over 600 patients early in 1914 . If it is to be presumed that the means of finding the patients, i.e., through chiefs and headmen were the same in $1894-95$ as in 1913-14, it appears that the incidence of the disease was trebled in a period of nineteen years.

In April, 1929, native inspectors trained in the diagnosis of leprosy were appointed to travel about on horseback searching villages for cases of leprosy, visiting especially the relatives of patients who were or had been in the institution, and keeping discharged patients under observation.

Since the appointment of these inspectors a great improvement has taken place, at first towards clearing the territory of advanced and infective cases, and later towards diminishing the number of all cases existing outside of the institution. The great majority of the new patients are in a very early stage of the disease. About 50 patients are discharged as "arrested " cases every year, and, owing to their more favourable conditions for treatment on admission, it is expected that the number annually discharged will go on increasing.

There are still so many aged, advanced and incurable cases in the institution, relics of the past, that the annual death rate is as high as ten per cent. The population of the institution, which passed through a maximum of 754 in November, 1933, is slowly diminishing and now stands at 720. It is expected that the decline in the population will continue. About 200 patients are now accepting the latest form of injection treatment, the intradermal, with great regularity.

In addition to the compounds where the patients live, a village of fifteen sandstone and thatched rondavels was built on the farm in 1932, about a mile away, for convalescent and early-stage patients. It is usually occupied by from 50 to 70 patients nearing "arrest."

Emjanyana. The Emjanyana Leprosy Institution is situated in the Encobo district of the Transkei, and has accommodation for about 
900 , but the present population is about 650 . The extent of the institution's reserve is about 5.000 acres. The patients are accommodated in large compounds situated near the heart of the reserve, the male and female patients being kept apart, but allowed to visit each other under supervision. The institution aims at being as self-contained as possible. Large wattle plantations supply the fuel requirements, and the farm supplies the meat, milk and vegetables needed by the patients and staff.

The patients govern themselves. Patients breaking the rules are tried in patient's courts, and punishments usually take the form of fines, which are paid into the Patient's Recreation Fund. The advantages arising from this system of self-control are many. The patients are induced to take a personal interest in the management of the institution and to understand thoroughly the rules. Wrong-doers get little sympathy from the patients, for it is they who mete out the punishment. Friction between the officials and the patients is reduced to a minimum. The chief advantage of the system lies in the fact that the patients feel that they are co-operating with the Government in the management of the institution and they respect themselves as a self-governing community.

M'Kambati. The M'Kambati Leprosy Institution, situated on the coast in the Lusiksiki district, was established in 1920, to serve Eastern and Western Pondoland. The usual number of inmates is about 260, and the discharge rate, which fluctuates slightly, is in the vicinity of 25 per cent. Medical and nursing services are supplied on contract by the Holy Cross Medical Mission (Anglican), situated 26 miles inland. The medical officers' services are on a visiting basis, but the nursing sisters are in residence.

The patients are afforded a very generous measure of freedom within the confines of the 70 square miles comprising the leper reserve, and are encouraged and helped in their recreation and sport.

The system of government provides for the election of a Patients' Advisory Council, which body, further, is vested with certain minor executive duties. Employment is regarded as an essential to the promotion of contentment, and remunerative work, graded to the worker's capacity, is found for the able and willing. For the younger inmates there is a school, staffed from amongst the more educated of the patients.

Ngomahuru, S. Rhodesia. The Ngomahuru Leprosy Hospital was started in 1929, under the charge of Dr. B. Moiser as Medical Superintendent. Previously sufferers from leprosy had been cared for by the Morgenster Mission. The hospital has dealt with over 1,100 patients, of whom about 400 have been discharged to their homes as "arrested" cases. At the moment there are 550 native cases and two whites in hospital.

The grounds occupy about 9,000 acres. The patients are all domiciled in villages and attend at the central hospital for treatment. The whole system is voluntary, and it is a matter for gratification that absentees are rare. 